\title{
Improving the therapeutic potential of endostatin by fusing it with the BAX BH3 death domain
}

\author{
RM Chura-Chambi ${ }^{1}$, MH Bellini ${ }^{1}$, JF Jacysyn ${ }^{2}$, LN Andrade ${ }^{3}$, LP Medina ${ }^{4}$, ÁRB Prieto-da-Silva ${ }^{5}$, GP Amarante-Mendes ${ }^{4}$ \\ and L Morganti ${ }^{*}, 1$
}

Endostatin (ES) inhibits angiogenesis, reducing tumor growth in animal models. However, it has low therapeutic effect in human clinical trials. BAX is a member of the BCL-2 family of proteins; its proapoptotic (BH3) domain interacts with other members of the family in the cytoplasm, to induce apoptosis. Here, we fused the BAX BH3 domain with murine ES, to enhance ES potency. Endothelial cells specifically internalize the fusion protein ES-BAX. The presence of the BAX domain enhances endothelial cell death by apoptosis by 1.8 -fold and diminishes microvessel outgrowth in the rat aortic ring assay by 6.5 -fold. Daily injections of $15 \mu \mathrm{g}$ of ES-BAX/g in tumor-bearing mice reduce tumor weight by $86.9 \%$ as compared with ES-treated animals. Co-immunoprecipitation assays confirmed that ES-BAX interacts with members of the BCL-2 family. Also, ES interacts with BCL-2, BCL- $X_{L}$, and BAK in endothelial cell lysates, suggesting a potential new mechanism for the apoptosis induction by ES. The superiority of the ES-BAX antiangiogenic effect indicates that this fusion protein could be a promising therapeutic alternative to treat cancer.

Cell Death and Disease (2014) 5, e1371; doi:10.1038/cddis.2014.309; published online 14 August 2014

Endostatin (ES) is a specific inhibitor of endothelial cell proliferation, migration, invasion, tube formation, angiogenesis, and tumor growth in animal models. ${ }^{1,2}$ Treatment with ES does not produce side effects or induce drug resistance. ${ }^{1}$ ES exerts its biological activities by binding to cell surface receptors, a process that triggers intracellular signaling cascades. Proteins such as nucleolin, matrix metalloproteinase 2, integrins, tropomyosin, glypicans, and laminin-1 are possible ES receptors that display binding affinities and that were described to be involved in the ES antiangiogenic function. ${ }^{3-7}$

The necessity to administer high ES levels on a daily basis $\left(15-600 \mathrm{mg} / \mathrm{m}^{2} /\right.$ day $),{ }^{8}$ the need to adjust doses, ${ }^{9}$ and the low antitumoral effect observed in clinical assays in humans ${ }^{10}$ have limited the use of ES to treat human cancer. Therefore, modifying the ES structure might improve its proapoptotic activity and provide better therapeutic protocols for human patients with cancer.

The B-cell lymphoma 2 (BCL-2) family of proteins constitutes regulators of the apoptosis intrinsic pathway. ${ }^{11,12}$ The BCL-2 members can be divided into three main subclasses that are partly defined by the homology shared within four conserved regions. These regions, termed BCL-2 homology $(\mathrm{BH})$ 1-4 domains, correspond to $\alpha$-helices with similar sequences that dictate protein structure and function. The antiapoptotic subfamily members BCL-2, B-cell lymphomaextra large $\left(B C L-X_{L}\right), B C L-W, M C L-1$, and $A 1$ contain three or four BH domains. The apoptosis effectors BCL-2-associated X-protein (BAX) and BCL-2 antagonist/killer (BAK) are subfamily relatives that possess structures in the domains $\mathrm{BH} 1$ through $\mathrm{BH} 3$; they closely resemble their prosurvival cognates. $^{13,14}$ The proapoptotic 'BH3-only' proteins are related to the other members by the short signature $\mathrm{BH} 3$ domain, which is essential for their killing function. ${ }^{15,16}$ The apoptotic switch operates through interactions between the proteins within the subfamilies. The structure of the prosurvival $B C L-X_{L}$ monomer revealed that its $\mathrm{BH} 1, \mathrm{BH} 2$, and $\mathrm{BH} 3$ domains are in close proximity and create a hydrophobic pocket that can accommodate a $\mathrm{BH} 3$ domain of the BAK proapoptotic member. ${ }^{17}$ In viable cells, the multidomains BAX and BAK exist as inactive monomers. Inactive BAX resides in the cytosol or loosely attaches to membranes; its C-terminal $\alpha 9$ helix occupies its hydrophobic pocket. ${ }^{13}$ Upon receipt of a death signal by a triggering $\mathrm{BH} 3$ helix, BAX transforms into a fully activated monomer that can propagate its own activation. ${ }^{18}$ Activated BAX translocates to the mitochondria, forming a putative homo-oligomer and generating pores that irreversibly damages these organelles. ${ }^{19}$ Consequently, proapoptogenic factors are released, activating the executioner caspases. ${ }^{20,21}$ The $\mathrm{BAX}$ BH3 domain confers BAX killing functionality. The minimal portion of BAK, critical for the heterodimerization and proapoptotic function, consists of a 15/16-amino acid peptide mapped to the $\mathrm{BH} 3$ domain. ${ }^{15,17,22}$

\footnotetext{
${ }^{1}$ Centro de Biotecnologia, Instituto de Pesquisas Energéticas e Nucleares - IPEN - CNEN/SP, São Paulo, Brazil; ${ }^{2}$ Laboratório de Investigação Médica LIM62, Faculdade de Medicina da, Universidade de São Paulo, São Paulo, Brazil; ${ }^{3}$ Departamento de Radiologia e Oncologia, Centro de Investigação Translacional em Oncologia, Instituto do Câncer do Estado de São Paulo, São Paulo, Brazil; ${ }^{4}$ Departamento de Imunologia, Instituto de Ciências Biomédicas, Universidade de São Paulo, São Paulo, Brazil and ${ }^{5}$ Laboratório de Imunopatologia, Instituto Butantan, São Paulo, Brazil

${ }^{*}$ Corresponding author: L Morganti, Centro de Biotecnologia, Instituto de Pesquisas Energéticas e Nucleares - IPEN - CNEN/SP, 2242 Professor Lineu Prestes Avenue, São Paulo 05508-000, Brazil. Tel: +55(11) 31339695; Fax: +55(11) 31339709; E-mail: Imorganti@ipen.br

Abbreviations: ES, endostatin; BH3, BCL-2 homology 3; BCL-2, B-cell lymphoma 2; BCL-X , B-cell lymphoma-extra large; BAX, BCL-2-associated X-protein; BAK, BCL-2 antagonist/killer; ES-BAX, ES fused to the BAX BH3 domain; ES-BAK, ES fused to the BAK BH3 domain; ES-BAX-ES, the ES BAX $\alpha$-helix is substituted by ES $\alpha$-helix; bFGF, basic fibroblast growth factor

Received 10.10.13; revised 22.5.14; accepted 10.6.14; Edited by H-U Simon
} 
Impaired apoptosis is a critical step in tumor development. Enhanced levels of the prosurvival BCL-2 family members or, alternatively, the loss or inactivation of the pro-death relatives frequently occur in cancer. ${ }^{23}$ Therefore, scientists have designed strategies to induce downstream apoptotic events that could overcome the inhibition of tumor cells apoptosis by either delivering proapoptotic $\mathrm{BH} 3$ peptides $^{24,25}$ or using compounds that function as cell permeable, small molecular mimics of the $\mathrm{BH} 3$ domain. ${ }^{26}$ However, there is concern about the therapeutic use of proapoptotic $\mathrm{BH} 3$ or its mimetics because of the lack of specificity to tumor cells, possibly prompting to greater toxicity to normal cells. Inducing an imbalance in favor of cell death by raising the levels of the proapoptotic $\mathrm{BH} 3$ peptide, is an interesting strategy, especially in cells with normal levels of the antiapoptotic BCL-2 proteins, which is the case of cells of tumor vasculature.

In the present study, we produced three chimerical recombinant proteins based on the core of the ES fused with the $\mathrm{BH} 3$ domains of the proapoptotic proteins BAK and BAX as a means to target these proteins. Such proteins display enhanced proapoptotic properties toward the tumor endothelium, avoiding damage to normal tissues. In addition, we determined if ES and ES-BAX interact with members of the BCL-2 family in endothelial cell lysates.

\section{Results}

ES, ES-BAX, ES-BAK, and ES-BAX-ES: expression, refolding, and purification. To target tumoral neovasculature, we engineered recombinant fusion proteins containing the full-length ES attached to the BAX or BAK deathpromoting domains. We named the mutant proteins ES-BAX (ES fused to the BAX BH3 domain) and ES-BAK (ES fused to the BAK BH3 domain), which consisted of ES, two Gly residues (to give flexibility to the peptide), and BAX or BAK amphipathic $\alpha$ helices containing 16 residues mapped to the $\mathrm{BH} 3$ domain. In the mutant protein ES-BAX-ES (the ES BAX $\alpha$-helix is substituted by ES $\alpha$-helix), we maintained the first two residues of the ES $\alpha$-helix 1 and substituted the sixteen following residues in the $\mathrm{BAX} \mathrm{BH} 3$ domain. With this configuration, we retained the Cys residue in ES position C33, because Cys is the natural sixth residue of the BAX peptide (Figure 1a). Figure 1b illustrates the hypothetical model of ES and the hybrid proteins. In ES-BAX, the BAX a

ES
ES-BAX
ES-BAK ES-BAK
ES-BAX-ES ES
ES-BAX
ES-BAK
ES-BAX-ES ES-BAX-ES ES
ES-BAX
ES-BAK ES-BAX
ES-BAK
ES-BAX-ES ES ES-BAK (1)

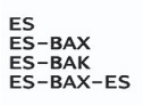
ES-BAX-ES

$$
1
$$

HTHQDFQPVL HLVALNTPLS GGMRGIRGAD FQCFQQARAV GLSGTFRAFL HTHQDFQPVL HLVALNTPLS GGMRGIRGAD FQCFQQARAV GLSGTFRAFL HTHQDFQPVL HLVALNTPLS GGMRGIRGAD FQCFQQARAV GLSGTFRAFL HTHQDFQPVL HLVALNTPLS GGMRGIRKKL SECLKRIGDE LDSGTFRAFL 51
SSRLQDLYSI VRRADRGSVP IVNLKDEVLS PSWDSLFSGS QGQLQPGARI SSRLQDLYSI VRRADRGSVP IVNLKDEVLS PSWDSLFSGS QGOLOPGARI SSRLQDLYSI VRRADRGSVP IVNLKDEVLS PSWDSLFSGS QGQLQPGARI SSRLQDLYSI VRRADRGSVP IVNLKDEVLS PSWDSLFSGS QGQLQPGARI

101

101 FSFDGRDVLR HPAWPQKSVW HGSDPSGRRL MESYCETWRT ETTGATGQAS FSFDGRDVLR HPAWPQKSVW HGSDPSGRRL MESYCETWRT ETTGATGQAS FSFDGRDVLR HPAWPOKSVW HGSDPSGRRL MESYCETWRT ETTGATGQAS

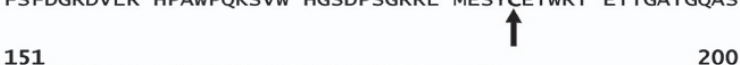

151

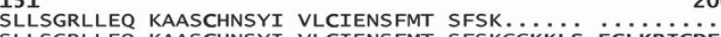

SLLSGRLLEQ KAASCHNSYI VLCIENSFMT SFSKGGKKLS ECLKRIGDEL SLLSGRLLLEQ KAASCHNSYI VLCIENSFMT SFSKGGGOVG RQLAIIGDDI SLLSGRLLEQ KAASCHNSYI VLCIENSFMT SFSK............... 201

Dis $\uparrow \uparrow$

$\underline{\underline{N R}}$

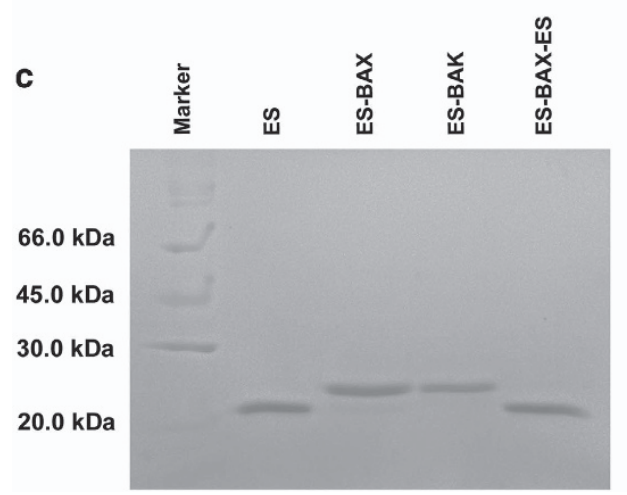

b ES

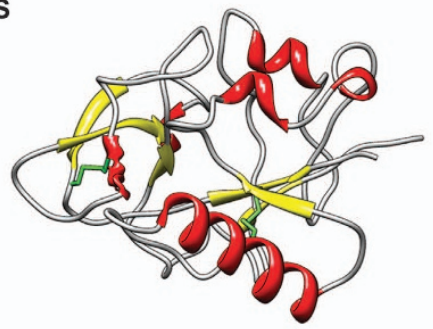

ES-BAX-ES
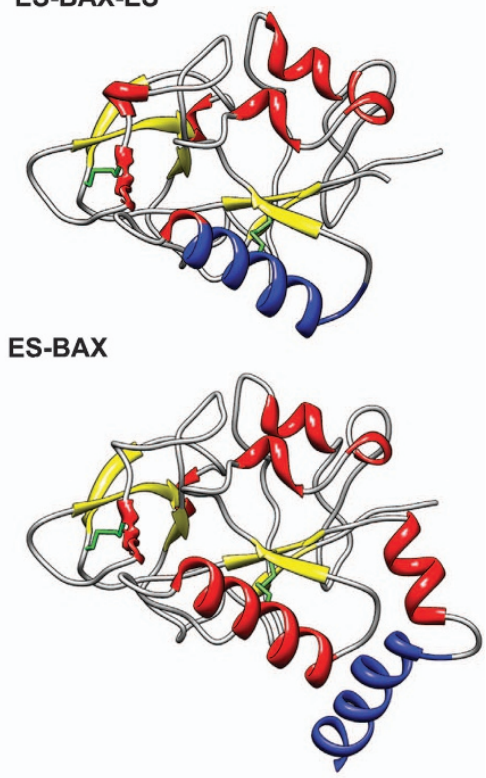

Figure 1 ES, ES-BAX, ES-BAK, and ES-BAX-ES. (a) Alignment of the primary sequences of ES and the hybrid proteins. The ES $\alpha$-helix 1 is indicated. The segments corresponding to the BAX or BAK BH3 domain are underlined. The cysteine residues involved in disulfide bonds (C33-C173 and $\mathrm{C} 135-\mathrm{C} 165)$ are indicated by arrows. (b) Cartoon representation of ES and hybrid proteins. ES $\alpha$-helices are shown in red, BAX BH3 $\alpha$-helices are shown in blue, $\beta$-sheets are shown in yellow, and disulfide bridges are shown in green. (c) Refolded and purified ES and hybrid proteins analyzed by SDS-PAGE 
$\mathrm{BH} 3 \alpha$-helix appears as an addition at the $\mathrm{N}$-terminal end of the fusion protein; in ES-BAX-ES, the BAX $\alpha$-helix substitutes the $E S \alpha$-helix. In both configurations, the disulfide bonds are theoretically maintained to mimic the ES.

We expressed high levels of the recombinant proteins ES, ES-BAX, ES-BAK, and ES-BAX-ES as inclusion bodies in Escherichia coli, and then we refolded and purified them. ES-BAX-ES presents a molecular weight similar to that of ES (21.5 kDa), while ES-BAX (23.5 kDa) and ES-BAK (23.4 kDa) have slightly higher molecular weight due to the 18 extra amino acids that they contain (Figure 1c). Compared with the other three recombinant proteins, ES-BAX-ES is less stable, which may have contributed to the lower yield observed during its expression and purification (data not shown).

Endothelial cells internalize ES and the fusion proteins. Endothelial cells specifically internalize ES. ${ }^{2,4}$ To determine whether the fusion proteins behave similarly, we incubated $\mathrm{C}-\mathrm{PAE}$ cells with the biotinylated proteins for $2 \mathrm{~h}$ at $37^{\circ} \mathrm{C}$. We viewed cell-associated ES, ES-BAX, ES-BAK, and ES-BAXES with Alexa 488-conjugated streptavidin (Molecular Probes, Eugene, OR, USA) in fixed and permeabilized cell preparations. According to Figure 2a, C-PAE cells but not $\mathrm{NIH} / 3 \mathrm{~T} 3$ fibroblasts internalize the four recombinant proteins,

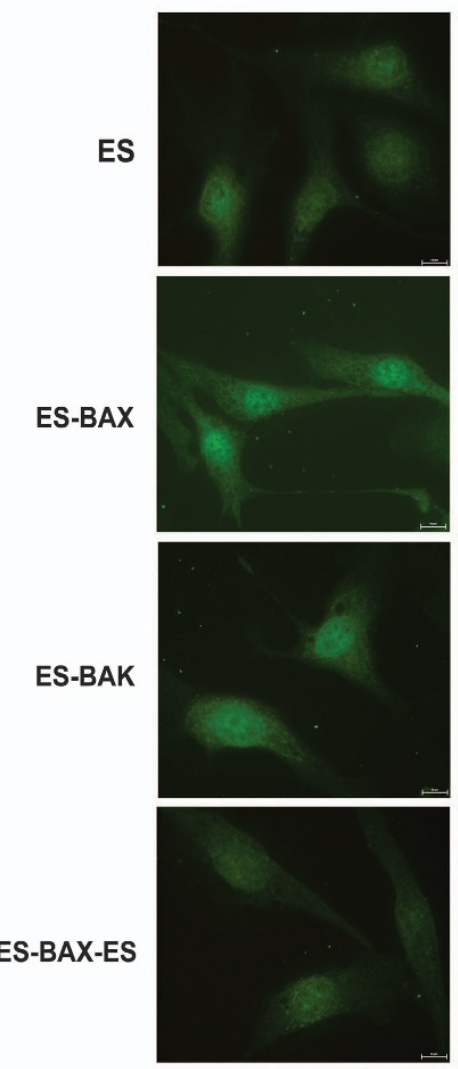

Alexa 488
C-PAE
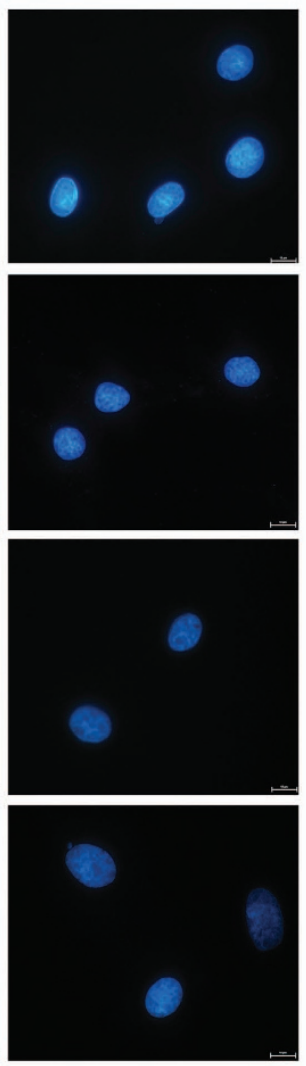

DAPI
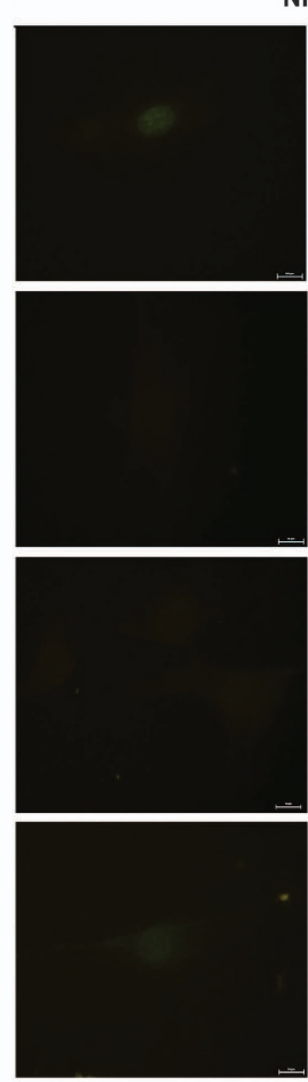

Alexa 488
$\mathrm{NIH}$
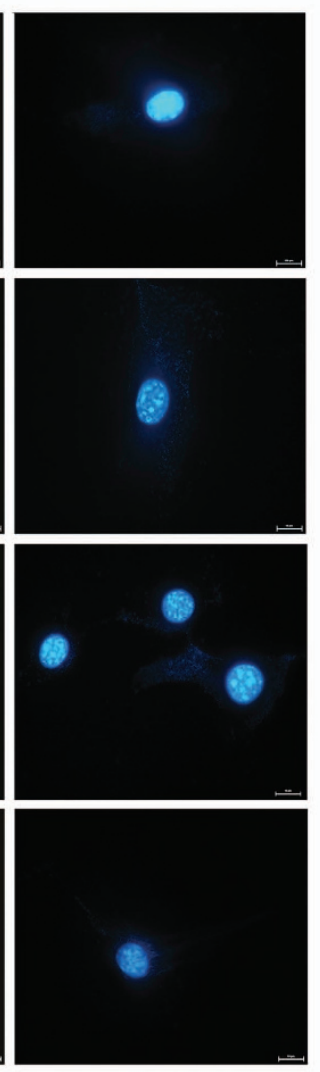

DAPI

b

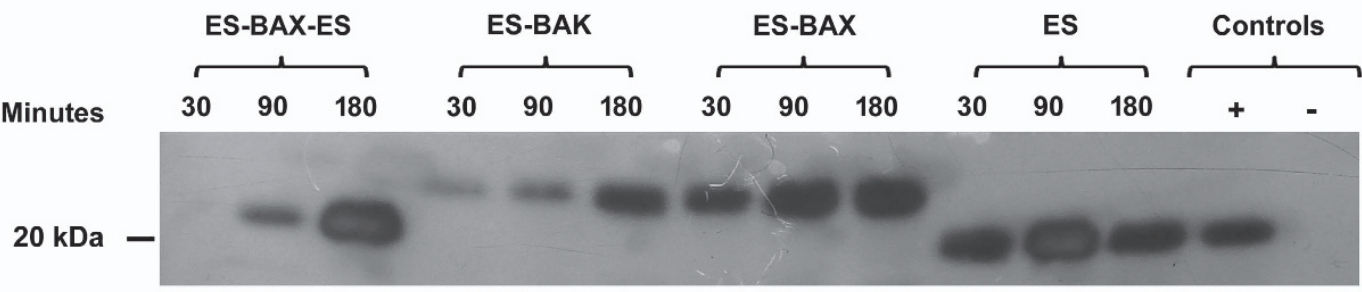

Beta actin

Figure 2 Internalization of ES, ES-BAX, ES-BAK, and ES-BAX-ES by endothelial cells. (a) C-PAE or NIH 3 T3 cells were incubated at $37^{\circ} \mathrm{C}$ for $2 \mathrm{~h}$ with $10 \mu \mathrm{g} / \mathrm{ml}$ of the biotynilated proteins: ES, ES-BAX, ES-BAK, or ES-BAX-ES. The cells were then fixed, permeabilized, and incubated with Alexa 488 conjugated with streptavidin. The nucleuses were stained with DAPI. The cells were analyzed under a fluorescence microscope. Scale bar: $10 \mu \mathrm{m}$. (b) Western blot of endothelial C-PAE cells incubated with $10 \mu \mathrm{g} / \mathrm{ml}$ of the indicated proteins at $37^{\circ} \mathrm{C}$ and detected by anti-ES antibody. Control $(+)$ : ES; control $(-)$ : lysate of cells incubated with ES that were immediately processed for western blot $(t=0 \mathrm{~min})$ 
indicating that the endothelial cells have the ability to specifically internalize the hybrids, similarly to wild-type ES. As described elsewhere, ${ }^{27}$ ES is internalized through endocytic vesicles and further transported into the nuclei. Apparently, nuclear translocation is more efficient for the variants ES-BAX and ES-BAK as compared with ES (Figure 2a). The presence of granules that possibly indicate endocytic vesicles within the cells treated for $1 \mathrm{~h}$ with ES, while the proteins ES-BAX and ES-BAK are more homogeneously distributed within the cytoplasm (Supplementary Figure1) also suggest that the routes for ES-BAX and ES-BAK within the cells are different from that of the wild-type protein. Internalization of ES and fusion proteins were also observed for HUV-EC-C human endothelial cells (not shown).

We cultivated endothelial cells (C-PAE) in the presence of each protein for 30,90 , or $180 \mathrm{~min}$ at $37^{\circ} \mathrm{C}$, followed by extensive washings and total cell lysis. We detected recombinant proteins, which represent bound and internalized components, by western blot using the anti-ES antibody. Although the cell-associated recombinant proteins are different at early time points, at $180 \mathrm{~min}$ the hybrid proteins exist at levels similar to or higher than those of ES (Figure 2b). The differences in the internalization kinetics may suggest that ES and its hybrid variants use different endocytic routes.

The presence of the BAX BH3 domain enhances ES potency. ES induces apoptosis in endothelial cells. ${ }^{28}$ To verify whether the presence of the BAK or BAX proapoptotic domains enhances the ES ability to induce endothelial cell death, we performed flow cytometry analysis of the propidium iodide-stained HUV-EC-C endothelial cells. Cells treated with the fusion proteins containing the BAX domain present higher degree of apoptosis as compared with cells treated with the same amount of ES. ES-BAX and ES-BAXES induce cell death at rates of $63.9 \%$ and $61.0 \%$, respectively, although $\mathrm{ES}$ only induces cell death at a rate of $35.1 \%$ (Figure 3a). Cells treated with ES-BAK behave more similarly to cells treated with ES, at a rate of $44.4 \%$. Importantly, all the recombinant proteins induce caspase-3 activation, as shown in Figure $3 b$.

To verify whether the presence of BAK or BAX proapoptotic domains enhances the ability of ES to induce endothelial cell viability loss, we incubated C-PAE cells with recombinant proteins and assessed cell viability by the MTS assay (Promega, Madison, WI, USA). A reduction in cell viability was observed for treatment of endothelial cells with $6.25 \mu \mathrm{g} / \mathrm{ml}$ ES and ES-BAX in a dose-response curve and the decrease in cell viability was stabilized with treatment of the cells with $25 \mu \mathrm{g} / \mathrm{ml}$ (Figure 3c). Incubation of the cells with $25 \mu \mathrm{g} / \mathrm{ml}$ ES and ES-BAK diminishes cell viability to the same extent: $76.1 \%$ as compared with the untreated control (100\% viability). The presence of the BAX domain significantly raises ES activity - the number of viable cells decreases to $50.0 \%$ and $65.8 \%$ after treatment with ESBAX and ES-BAX-ES, respectively (Figure 3d). Endothelial cell viability in response to treatment with ES and ES-BAX was also determined for different time points. The cells presented a decline of viability in response to treatment with ES-BAX for $3 \mathrm{~h}$, while the decrease of viability was observed only after $6 \mathrm{~h}$ of treatment with ES (Figure 3e). Inhibition of microvessel outgrowth of the ex vivo rat aortic ring in Matrigel (Becton-Dickinson,
San Diego, CA, USA) with dose-dependent effects helps to evaluate the biological activity of murine ES. ${ }^{29}$ We used the aortic ring assay to examine the effect of the recombinant fusion proteins investigated herein. As expected, compared with untreated rings, ES abate outgrowths from the aortic rings. In agreement with our previous results, ES-BAX and ES-BAX-ES induce a more potent antiproliferative effect on microvessels. ES-BAX almost completely prevents the outgrowth of rat aortic endothelial cells (Figure 4a). Quantitative image analysis confirmed that ES-BAX and ES-BAX-ES display increased biological activity as compared with ES (Figure 4b). However, as expected, ES-BAK presents effects similar to those of ES.

ES-BAX potently suppresses in vivo tumor growth. Finally, we investigated the effect of in vivo therapy with ESBAX on a mouse model of allograft adenocarcinoma renal tumor. The dosage of administered ES (15 $\mu \mathrm{g} / \mathrm{g}$ mice) was chosen based on the literature ${ }^{30}$ to induce incomplete tumor growth inhibition. As expected, compared with the untreated group, tumor growth diminishes in the group treated with ES. Moreover, consistent with the results described above, mice treated with ES-BAX experience more pronounced decrease in tumor volume (Figure $5 \mathrm{a}$ ). In three of the five mice treated with ES-BAX, tumor growth either stabilizes or decreases, which does not occur in any of the animals belonging to the other groups. The average tumor weights were $2.63 \pm 1.19 \mathrm{~g}$ (untreated), $1.34 \pm 0.39 \mathrm{~g}(\mathrm{ES})$, and $0.175 \pm 0.062 \mathrm{~g}$ (ES-BAX; Figure $5 \mathrm{~b}$ and $\mathrm{c}$ ), which correspond to a remarkable $93.3 \%$ and $86.9 \%$ reduction in tumor weight for the ES-BAX-treated group as compared with the untreated control group and the EStreated group, respectively. To exclude the possibility that ES or ES-BAX can directly affect the renal carcinoma cells, we performed an in vitro viability assay (MTS). We did not detect any loss of cell viability upon incubation with ES or ES-BAX (not shown), as opposed to the results obtained with the endothelial cells (Figure 3c). Hence, as expected, ES-BAX exerts an indirect effect on the tumors.

ES, ES-BAX, and ES-BAK can bind to cellular BCL-2 and $\mathbf{B C L}-\mathbf{X}_{\mathbf{L}}$. The ability of proapoptotic BH3 peptides to induce cell death depends on their capacity to interact with the proapoptotic members of the BCL-2 family of proteins. ${ }^{31}$ Therefore, we examined whether ES and the hybrid proteins ES-BAX and ES-BAK can bind to the protective proteins BCL2 and $B C L-X_{L}$ and to the proapoptotic proteins $B A X$ and BAK from an endothelial cell lysate. In agreement with our expectations, the hybrid proteins ES-BAX and ES-BAK coimmunoprecipitate along with BCL-2, BCL- $X_{L}, B A X$, and BAK present in the lysate of endothelial cells (Figure 6). The binding between ES-BAK, and ES-BAX with the cellular proteins $B C L-2$ and $B C L-X_{L}$ were confirmed by reciprocal assay. Surprisingly, ES also co-immunoprecipitates with the two antiapoptotic proteins and with BAK (Figure 6). To the best of our knowledge, this is the first observation that ES can directly interact with members of the BCL-2 family. The ES binding to proteins belonging to the BCL-2 family was unexpected and very interesting, possibly opening new perspectives for understanding the ES mechanism of action. Probably the domain of ES responsible for the binding to $B A K / B C L-2 / B C L-X_{L}$ diverges from the domain of ES-BAX 


\section{a}

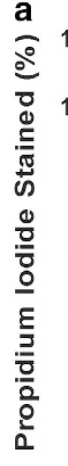

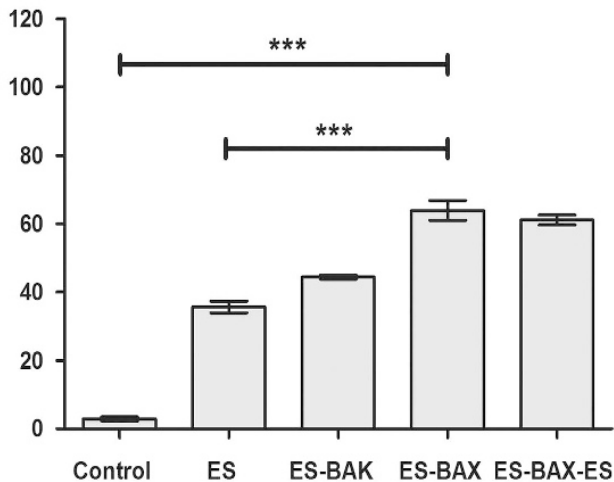

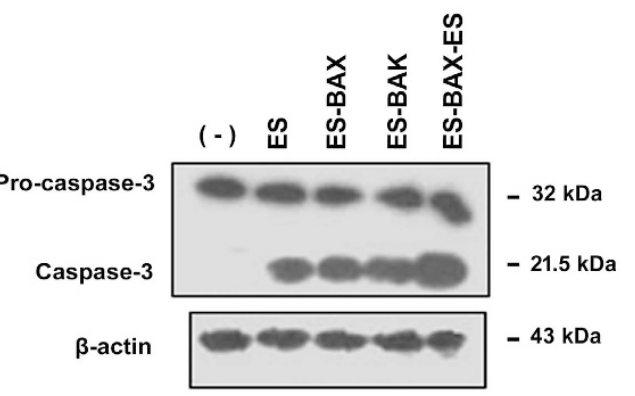

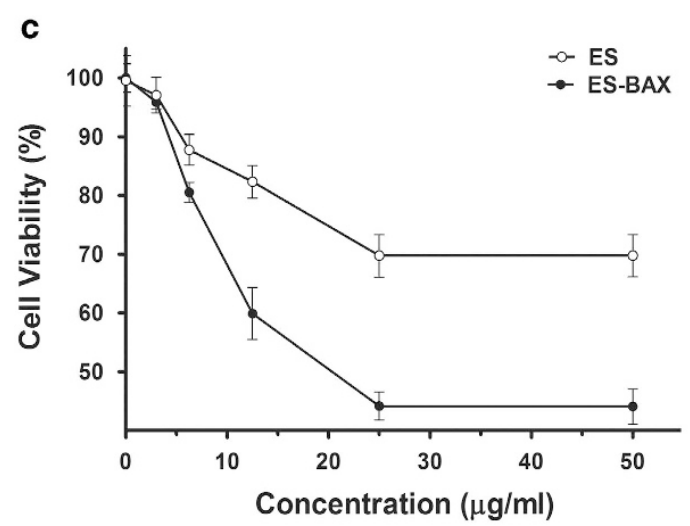

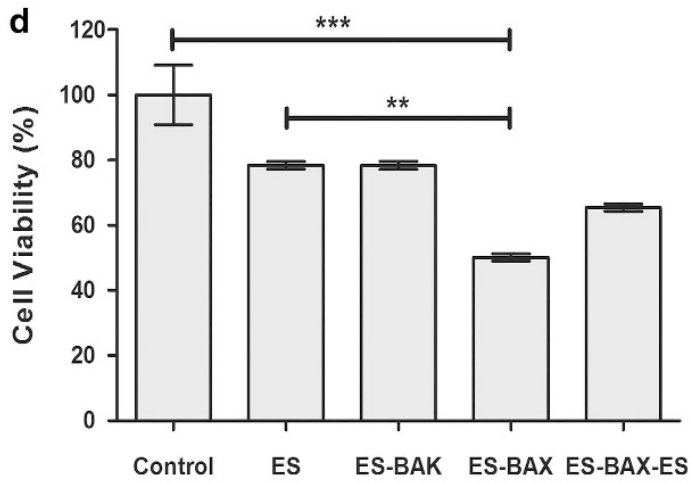

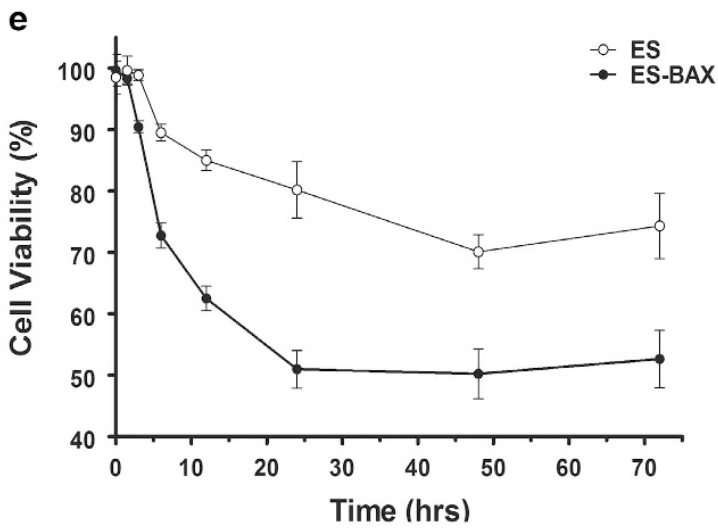

Figure 3 Effect of ES, ES-BAX, ES-BAK, and ES-BAX-ES on endothelial cells. (a) C-PAE cells were incubated in the presence or absence of $20 \mu \mathrm{g} / \mathrm{ml}$ of either protein for $16 \mathrm{~h}$. The cells were trypsinized and stained with propidium iodide. Fluorescence of individual nuclei was measured by flow cytometry. Each sample was analyzed in triplicate. Error bars: mean \pm S.E.M. The statistical significance of differences between the groups was assessed with one-way ANOVA with Bonferroni post-test, ${ }^{* \star *} P<0.001$. (b) Analysis of caspase-3 activation in C-PAE cells untreated or treated for $24 \mathrm{~h}$ with $20 \mu \mathrm{g} / \mathrm{ml}$ of each protein. $\beta$-Actin was used as a loading control. (c) C-PAE cells were incubated in the absence or presence of 3.12-50 $\mu \mathrm{g} / \mathrm{ml}$ of either protein for $72 \mathrm{~h}$, and relative cell viability was determined by the MTS assay. The mean absorbance of the control group at $495 \mathrm{~nm}$ was set as 100\% viability. Each sample was analyzed in triplicate. (d) C-PAE cells were incubated in the absence or presence of $25 \mu \mathrm{g} / \mathrm{ml}$ of either protein for $72 \mathrm{~h}$, and relative cell viability was determined by the MTS assay. (e) C-PAE cells were incubated in the presence or absence of $25 \mu \mathrm{g} / \mathrm{ml}$ of either protein for $45 \mathrm{~min}$ to $72 \mathrm{~h}$, and relative cell viability was determined by the MTS assay. Error bars: mean \pm S.E.M. The statistical significance of differences between the groups was assessed by one-way ANOVA with Bonferroni post-test, ${ }^{* *} P<0.01 ;{ }^{* \star *} P<0.001$

responsible for the binding to $B A X$ and to BAK/BCL-2/BCL- $X_{L}$. These issues need to be properly investigated in future studies.

\section{Discussion}

In the present study, we circumvented the difficulties related to the lack of specificity of inducers of tumor death by targeting endothelial cells of the tumor vasculature; in other words, we indirectly targeted tumors. The $\mathrm{BH} 3$ domains of proapoptotic proteins were targeted to tumor endothelia by the presence of the ES domain, a protein that was previously shown to be able to be specifically internalized by angiogenic endothelial cells. ${ }^{2}$ Here, we verified that the endothelial cells specifically internalize the three fusion proteins ES-BAX, ES-BAK, and ES-BAX-ES at least as efficiently as they internalize ES. 
a

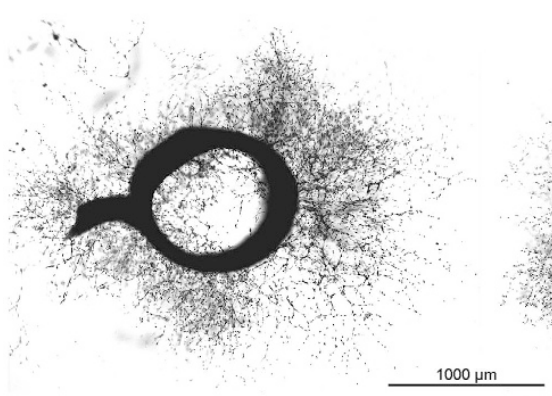

ES-BAK

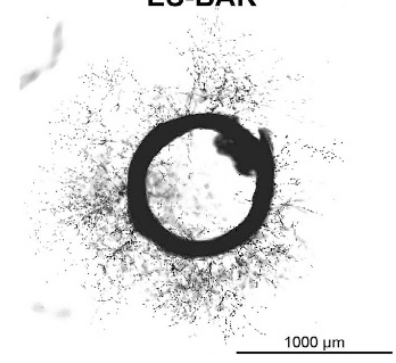

ES

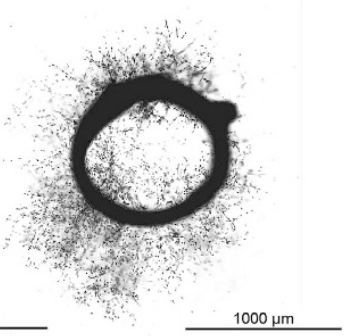

ES-BAX

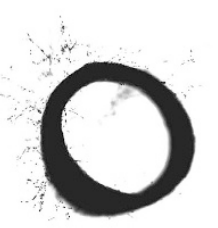

$1000 \mu \mathrm{m}$

ES-BAX-ES

b

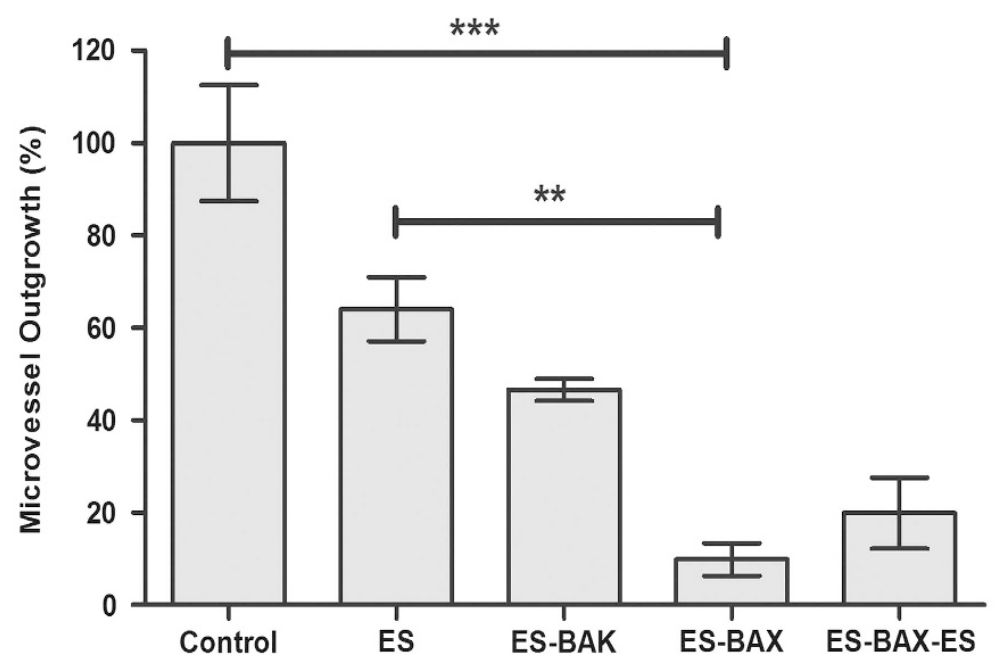

Figure 4 Effect of ES, ES-BAX, ES-BAK, and ES-BAX-ES in the ex vivo rat aortic ring assay. Ring sections were cut out from freshly isolated aorta of euthanized rats. The rings were cultivated in Matrigel, in the absence or presence of $10 \mu \mathrm{g} / \mathrm{ml}$ of each protein for 7 days. The aortic rings and the angiogenic sprouting were stained with MTT and photographed. (a) Photographs from representative rings from assays performed in triplicate. Scale bar: $1000 \mu \mathrm{m}$. (b) Quantification of microvessel outgrowth in each condition. The mean of the pixels number of the outgrowth of the control group was set as $100 \%$. Error bars: mean \pm S.E.M. The statistical significance of differences between the groups was assessed by one-way ANOVA with Bonferroni post-test, ${ }^{* *} P<0.01 ;{ }^{* *} P<0.001$. This assay was performed three times

Another relevant finding is that unrelated cells do not internalize the hybrid proteins. Enhanced levels of antiapoptotic or decreased levels of proapoptotic Bcl-2 members in tumor cells are common obstacles to cancer chemotherapy. ${ }^{32,33}$ To overcome difficulties pertaining to the imbalance in the tumor cell apoptotic pathway, we therapeutically targeted cells that present normal levels of the BCL-2 relatives, the endothelial cells. The presence of the $\mathrm{BAX} \mathrm{BH} 3$ domain significantly improves the in vitro activity of the ES recombinant proteins. The ex vivo aorta rings assay reveals a similar effect, showing the antiangiogenic activity of this protein. Most importantly, ESBAX substantially reduces tumor volumes in mice bearing renal tumors: by $88 \%$ and $71 \%$ as compared with untreated mice and ES-treated mice, respectively.
ES presents increased activity when the BAX fragment is present, either as a C-terminal fragment or by replacement of the ES native $\alpha$-helix. A noticeable biochemical difference exists between the effectors of the apoptotic pathways BAK and $B A X$ in healthy cells: BAX is largely cytosolic or loosely associates with mitochondria, whereas BAK is an integral membrane protein on the cytosolic face of the mitochondrion and the endoplasmic reticulum. However, BAX and BAK physiologically appear to be largely redundant in function. ${ }^{19}$ The presence of the BAK BH3 domain in the ES-BAK construct does not enhance the cytotoxic effect, indicating that the presence of a peptide with 16 amino acids per se does not suffice to improve ES activity. These results reinforce that the BAX BH3 apoptotic pattern accounts for the enhanced 


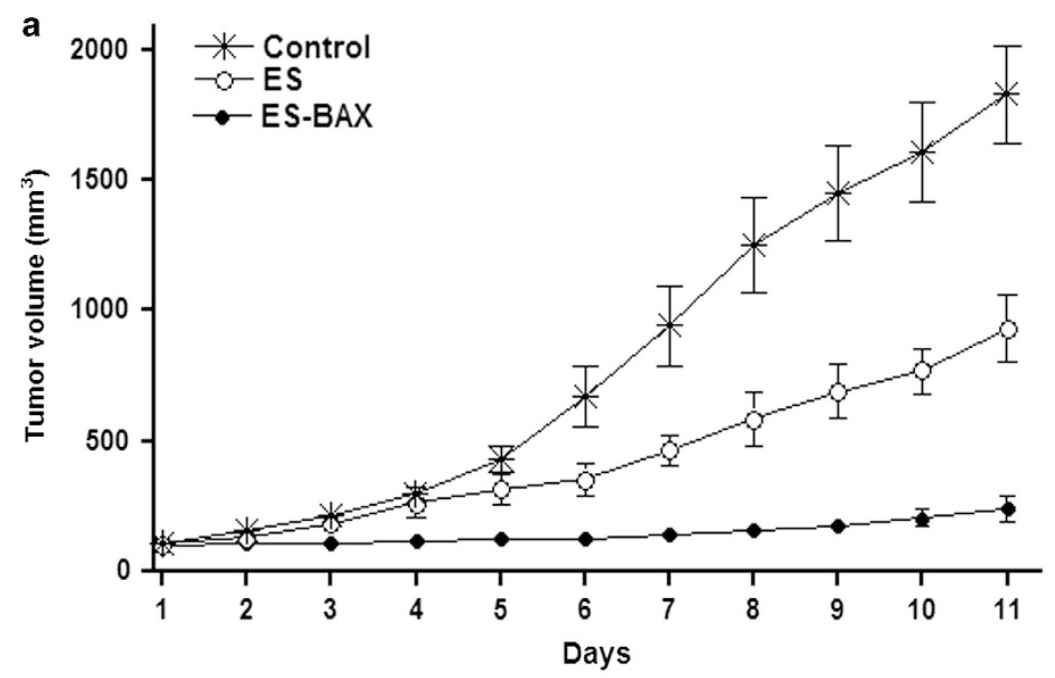

b

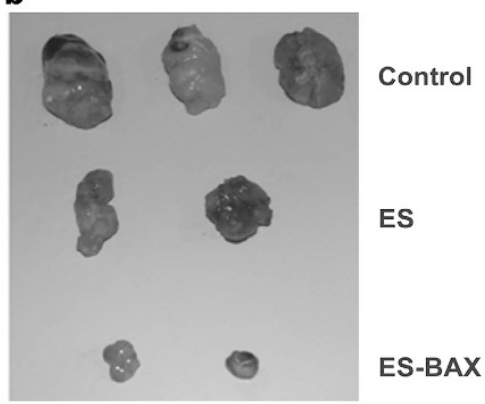

C

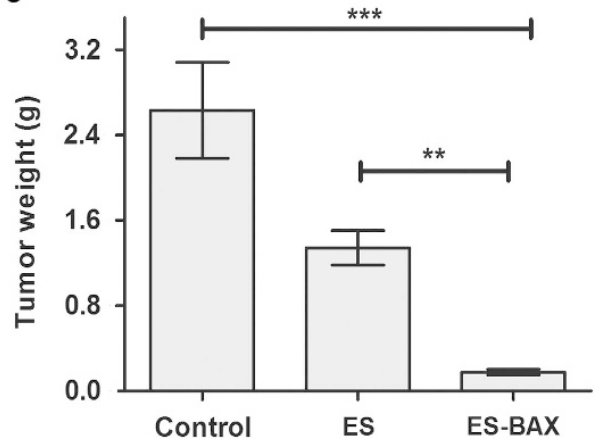

Figure 5 Effect of ES and ES-BAX on tumor growth. BALB/c mice ( $n=5$ per group) received s.c. injections with $2 \times 10^{5}$ Renca cells. When tumors reached $100 \mathrm{~mm}^{3}$, mice received daily s.c. injections of buffer or $15 \mu \mathrm{g}$ of either ES or ES-BAX/g of mice. On day 11 after beginning of the treatment of the first set of mice, the animals were euthanized, and the tumors were removed, weighed, and photographed. This procedure was repeated until the treatment of all of the animals was concluded. (a) Kinetics of tumor growth during the 10-day treatment. (b) Photographs from representative tumors withdrawn on day 11 after the beginning of the treatment. (c) Average tumor weight on day 11. Error bars: mean \pm S.E.M. Statistical significance was determined using a Student's $t$-test (two-tailed), ${ }^{* \star} P<0.005 ;{ }^{\star * \star} P<0.0001$. This assay was performed twice

activity of the hybrid proteins ES-BAX and ES-BAX-ES. However, further studies are necessary to understand the different effects of the BAX and BAK BH3 domains on ES toxicity to endothelial cells.

$\mathrm{BAX}$ and BAK present the hydrophobic side chain of the $\mathrm{BH} 3$ helix, which is involved in binding to the antiapoptotic family members, facing towards the core of the protein. Upon engagement, which occurs by triggering the $\mathrm{BH} 3$ helix, the unstructured loop between $\alpha$-helices 1 and 2 is displaced, the carboxy-terminal helix 9 is mobilized for membrane translocation, ${ }^{18}$ and the BAX BH3 domain is exposed. Consequently, the death signal propagates through an auto-activating interaction that involves the triggering site of inactive BAX monomers. ${ }^{34}$ An alternative hypothesis is that exposed proapoptotic $\mathrm{BH} 3$ domains of $\mathrm{BAX}, \mathrm{BAK}$, or $\mathrm{BH} 3-$ only proteins can bind to the hydrophobic surface groove of the prosurvival family members and promote apoptosis by releasing the active proapoptotic proteins from their antiapoptotic counterparts. ${ }^{35,36}$ Apoptosis occurs when BAX or BAK suffers from major conformational changes, followed by homo-oligomerization. These alterations can generate the 'apoptotic pore' in the mitochondrial outer membrane and release cytochrome $c$. Obviously, ES-BAX does not participate in BAX oligomerization because it lacks the domains involved in oligomerization or the membrane insertion that exists in the integral BAX protein. However, possibly the proapoptotic $\mathrm{BH} 3$ domain exposed in the hybrid protein ES-BAX interacts with intracellular BAX directly and activates it. An alternative is that the proapoptotic domain interacts with the prosurvival proteins, releasing activated BAX. The released BAX then undergoes homooligomerization, to form the mitochondrial outer membrane pores that induce cytochrome $c$ release and endothelial cells apoptosis.

It was described that $\mathrm{BAX} \mathrm{BH} 3$ peptide interfere with $\mathrm{BAX}$ / $B C L-2$ and $B A X / B C L-X_{L}$ heterodimerization in vitro and promote cytochrome $c$ release from mitochondria isolated from Jurkat, HL-60, U937, and PC-3 cells. ${ }^{22}$ The BAX BH3 peptide also potently interfere with both $B A X / B C L-2$ and $B A X /$ $B C L-X_{L}$ interactions in vitro. This interference correlates with the ability of this peptide to overcome BCL-2 overexpression, as shown by the induction of cytochrome $c$ release from mitochondria of Jurkat T-leukemic cells overexpressing BCL-2. ${ }^{31}$ Apart from the length and amino acid composition of the $\mathrm{BH} 3$ peptides, their ability to form a stable helical structure is important to their high binding affinity, and there seems to exist a direct correlation between the tendency of $\mathrm{BH} 3$ peptides to form a helix and their affinity for the antiapoptotic proteins. However, the $\mathrm{BH} 3$ domain peptides 


\section{IP ES}

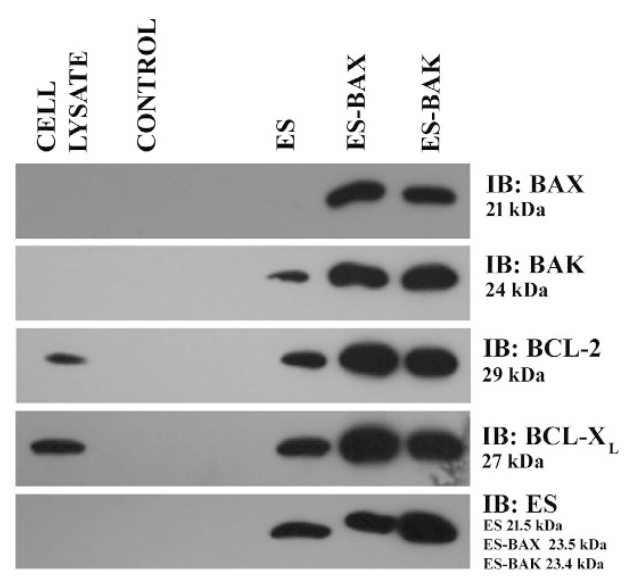

IP BCL-2

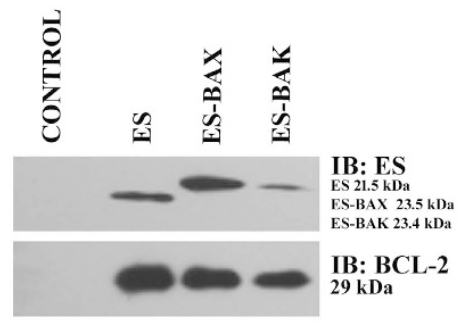

IP BCL-X

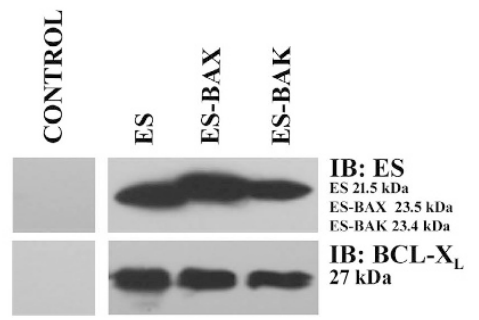

Figure 6 Interaction of ES, ES-BAX, and ES-BAK with members of the BCL-2 family. Whole cell lysates of $10^{7}$ endothelial cells (HUV-EC-C) were incubated in the absence or presence of $100 \mu \mathrm{g} / \mathrm{ml}$ ES, ES-BAX, or ES-BAK. The ES, ES-BAX, or ES-BAK complexes bound to cellular proteins (BCL-2, BCL- $X_{L}, B A X$, or BAK) were incubated with the antibodies indicated for co-immunoprecipitation, captured on Protein $G$ agarose beads, and subsequently subjected to SDS-PAGE. The complexes were detected by immunoblotting with the indicated antibodies. Similar blots were probed with the same antibodies that were used for co-immunoprecipitation, to ensure that equivalent amounts of proteins were present in each reaction. Cell lysates were applied at equivalent volumes. Non-related monoclonal antibodies were used to control co-immunoprecipitation

of proapoptotic proteins are mostly unstructured in aqueous solution, ${ }^{22,37,38}$ whereas they adopt a well-defined helical conformation in experimentally determined complex structures. ${ }^{17,39-41}$ Therefore, the interaction between the BAX BH3 peptide in the hydrophobic groove of the antiapoptotic members of the BCL-2 family is feasible, even in the case whereupon the ES-BAX BH3 peptide does not present helical conformation in solution.

Many mechanisms of action have been proposed for ES. However, as far as we know, this is the first time that the direct interaction between $\mathrm{ES}$ and $\mathrm{BCL}-2, \mathrm{BCL}-\mathrm{X}_{\mathrm{L}}$, and BAK has been demonstrated (Figure 6). Further studies are necessary to determine whether the apoptotic effect of wt-ES on proliferating endothelial cells refers to its interaction with members of the BCL-2 family.

BH3-only proteins function either by binding to their prosurvival relatives, which prevents them from inhibiting $\mathrm{BAX}$ and $\mathrm{BAK}$, or by directly activating the apoptosis effectors. Although some BH3-only members engage only some of the prosurvival members, BIM and PUMA are potent inducers of cell death because they can engage all the prosurvival proteins $^{38}$ and directly activate BAX. ${ }^{18}$ It is likely that the $\mathrm{BH} 3$ domain of these proteins can serve as efficient effectors of apoptosis. Thus, further studies on hybrid proteins based on the ES core attached to the $\mathrm{BH} 3$ domain of the potent killer members of the $\mathrm{BH} 3$-only family are relevant and ongoing in our laboratory.

To our knowledge, this is the first time that the $\mathrm{BH} 3$ death domain has been examined as a fusion partner to target and induce apoptosis in non-tumor cells. Because BCL-2 overexpression is a common cause of multidrug resistance, our primary goal has been to improve the ES-mediated inhibition of tumor neovasculature. Here, we have provided definitive evidence of enhanced endothelial cell apoptosis and in vivo tumor regression by adding the BAX BH3 domain at the ES C-terminus.

\section{Materials and Methods}

Construction of plasmids, expression refolding, and purification of proteins. Hybrid proteins were generated by site-directed mutagenesis using the ES construct pETKH1 (ATCC No. 63404), which contains the sequence that codifies for the residues HAHHHHHHM, followed by the sequence that codifies for murine ES, as template. Coding sequences for two Gly residues, followed by the minimal sequence of the $\mathrm{BH} 3$ domain of the proapoptotic peptides BAX or BAK were inserted between the codon for the last amino acid of the ES gene and the stop codon. Site-specific mutagenesis was induced as previously described ${ }^{42}$ by respectively using the following primers: $5^{\prime}$-TCGACGGAGCTCG AATTCTAAGAGTCCAGTTCGTCACCGATACGTTTCAGGCATTCAGACAGTTTT TTACCACCTTTGGAGAAAGAGGTCAT-3' and 5'-TCGACGGAGCTCGAATTC TAAGAGTCCAGTTCGTCACCGATACGTTTCAGGCATTCAGACAGTTTTTTACC ACCTTTGGAGAAAGAGGTCAT-3'.

The primer $5^{\prime}$-AGGAAAGCCCGGAAGGTGCCAGAGTCCAGTTCGTCACCGA TACCGTTTCAGGCATTCAGACAGTTTTTTACGGATACCACGCATGCCT- $3^{\prime}$ was used for the mutagenesis procedure, substituting the DNA coding sequences of the $\alpha$-helix of ES with the $\alpha$-helix of the BAX BH3 domain. DNA sequencing was performed to confirm the expected mutations. All cDNAs were cloned into the pET28 (Merck Millipore, Darmstadt, Germany) to generate the expression plasmids pET-ES, pET-ES-BAX, pET-ES-BAK, and pET-ES-BAX-ES.

Vectors encoding $E S$ and the hybrid proteins were transformed into $E$. coli BL21 (DE3) cells and cultured in rich culture medium $(2 \mathrm{x}-\mathrm{HKSII})^{43}$ supplemented with $50 \mu \mathrm{g} /$ $\mathrm{ml}$ kanamycin at $37^{\circ} \mathrm{C}$, until the $\mathrm{OD}_{600 \mathrm{~nm}}$ reached the value of 3.0. IPTG (Sigma, St. Louis, MO, USA) was added to a final concentration of $0.5 \mathrm{mM}$. Following incubation at $37^{\circ} \mathrm{C}$ for $16 \mathrm{~h}$, the cells were harvested by centrifugation at $12000 \times \mathrm{g}$ for $10 \mathrm{~min}$, at $4^{\circ} \mathrm{C}$. The ES inclusion bodies and the three hybrids produced by $\mathrm{E}$. coli were refolded and purified by following previously described protocols. ${ }^{43}$

Internalization assays. Biotinylation of the proteins was achieved using sulfo-NHS-LC-Biotin (EZ-Link sulfo-NHS-LC biotinylation kit, Pierce, Rockford, IL, USA). C-PAE or NIH 3T3 cells (ATCC, CCL-209 and CRL-1658, respectively; $5 \times 10^{4}$ ) were cultured in glass coverslips in EMEM medium (Life Technologies Corporation, Grand Island, NY, USA) supplemented with $2 \%$ FBS for $24 \mathrm{~h}$. After $24 \mathrm{~h}$ of serum deprivation, the cells were incubated for $12 \mathrm{~h}$ in the same medium supplemented with $5 \mathrm{ng} / \mathrm{ml} \mathrm{bFGF}$. After 1 or $2 \mathrm{~h}$ of incubation in the same medium containing $10 \mu \mathrm{g} / \mathrm{mL}$ biotin-labeled ES, ES-BAX, ES-BAK, or ES-BAX-ES, the cells were washed twice with phosphate-buffered saline (PBS), permeabilized by 6-min incubation in ice-cold methanol, washed twice with PBS, and then blocked with $1 \%$ BSA in PBS for 40 min. The cells were then incubated with Alexa 
488-conjugated streptavidin (Life Technologies Corporation) for $45 \mathrm{~min}$ and washed with PBS five times. Vectashield mounting medium containing DAPI (4', 6-diamidino-2-phenylindole; Vector Laboratories, Burlingame, CA, USA) were applied to glass slides and coverslips were placed on it. The fields were photographed in a fluorescence microscope.

C-PAE cells $\left(5 \times 10^{4}\right)$ were cultured in 12-well plates in EMEM medium supplemented with $20 \%$ fetal bovine serum (FBS), $50 \mathrm{U} / \mathrm{ml}$ penicillin, $50 \mu \mathrm{g} / \mathrm{ml}$ streptomycin, and $2 \mathrm{mM} \mathrm{L-glutamine.} \mathrm{After} 24 \mathrm{~h}$, the medium was changed to EMEM supplemented with $2 \% \mathrm{FBS}, 10 \mathrm{ng} / \mathrm{ml}$ bFGF (RD systems, Minneapolis, MN, USA), and $10 \mu \mathrm{g} / \mathrm{ml} \mathrm{ES}$, ES-BAX, ES-BAK, or ES-BAX-ES at $37^{\circ} \mathrm{C}$. After different periods of time, the cells were washed three times in PBS, resuspended in SDS-PAGE sample buffer, and heated for $5 \mathrm{~min}$ at $95^{\circ} \mathrm{C}$. Protein samples were separated on $12 \%$ SDSpolyacrylamide gels under reducing conditions and electrotransferred to nitrocellulose membrane (GE Healthcare, Rapsgatan, Uppsala, Sweden). The membranes were incubated with rabbit anti-ES polyclonal antibody (AB1880, diluted 1:500, Merck Millipore), followed by incubation with horseradish peroxidase (HRP) conjugated to secondary antibody (Merck Millipore, diluted 1:5000). Immunodetection was carried out with the chemiluminescence reagent (Immobilon, Merck Millipore).

In vitro apoptosis detection. Apoptosis was quantified by analysis of the DNA content using flow cytometry. Briefly, $1.5 \times 10^{5} \mathrm{C}$-PAE cells were plated in six-well tissue culture plates in EMEM containing $20 \%$ FBS. After cell adhesion, the medium was replaced with medium containing $2 \% \mathrm{FBS}, 10 \mathrm{ng} / \mathrm{ml} \mathrm{bFGF}$, and $20 \mu \mathrm{g} / \mathrm{ml}$ ES, ES-BAX, ES-BAK, or ES-BAX-ES. After $16 \mathrm{~h}$ of incubation, cells were trypsinized, resuspended in $0.3 \mathrm{ml}$ of a hypotonic solution $(50 \mathrm{mg} / \mathrm{ml}$ propidium iodide, $0.1 \%$ sodium citrate, and $0.1 \%$ Triton X-100, Sigma), and kept at $4^{\circ} \mathrm{C}$ in the dark until they were examined. The fluorescence of individual nuclei was measured with a FACScalibur flow cytometer (Becton-Dickinson).

Analysis of caspase-3 activation. Caspase-3 activity was measured. Briefly, $4 \times 10^{5}$ C-PAE cells were maintained in EMEM medium containing $2 \%$ FBS for $24 \mathrm{~h}$. The medium was replaced with fresh medium containing $2 \% \mathrm{FBS}$, $10 \mathrm{ng} / \mathrm{ml} \mathrm{bFGF}$, and $20 \mu \mathrm{g} / \mathrm{ml}$ ES, ES-BAX, ES-BAK, or ES-BAX-ES. After $24 \mathrm{~h}$, all the cells (adherent or not) were collected and resuspended in SDS-PAGE sample buffer; the proteins were boiled for $5 \mathrm{~min}$, for denaturation. The proteins from the lysates were resolved electrophoretically on a 15\% SDS-PAGE and transferred to a nitrocellulose membrane (GE Healthcare, San Diego, CA, USA). The membrane was incubated with anticaspase-3 antibody (Santa Cruz Biotechnology, Santa Cruz, CA, USA) for $16 \mathrm{~h}$, washed, incubated with a secondary antibody conjugated with $\mathrm{HRP}$ for $1 \mathrm{~h}$, and washed again. Immunoreactive bands were visualized using an enhanced chemiluminescence system (Immobilon, Merck Millipore).

Cell Viability. C-PAE viability was evaluated by the MTS [3-(4,5-dimethylthiazol2-yl)-5-(3-carboxymethoxyphenyl)-2-(4-sulfophenyl)-2H-tetrazolium)] assay (Promega). Briefly, $5 \times 10^{3}$ C-PAE cells were plated in each well of a 96-well tissue culture plate in EMEM supplemented with $20 \%$ FBS in a final volume of $0.1 \mathrm{ml}$. After $24 \mathrm{~h}$, the medium was replaced with fresh medium containing $2 \% \mathrm{FBS}, 10 \mathrm{ng} / \mathrm{ml} \mathrm{bFGF}$ and $3.12-50 \mu \mathrm{g} / \mathrm{ml}$ ES, ES-BAX, ES-BAK, or ES-BAX-ES and incubated for $45 \mathrm{~min}$ to $72 \mathrm{~h}$. Cell viability was measured by addition of $20 \mu \mathrm{l}$ of an MTS $(0.2 \%) /$ PMS (0.092\%; phenazine methosulfate, $20: 1)$ solution and incubation for $2 \mathrm{~h}$ at $37^{\circ} \mathrm{C}$ in a humidified $5 \% \mathrm{CO}_{2}$ incubator. The microplates were read in a spectrophotometer at a wavelength of $495 \mathrm{~nm}$. The absorbance of the control group (without added protein) at $495 \mathrm{~nm}$ was set as $100 \%$ cell viability. Each sample was analyzed in triplicate.

Rat aortic ring assay. Each well of a tissue culture-grade plate (48 well) was covered with $150 \mu \mathrm{l}$ of cold Matrigel and allowed $30-45 \mathrm{~min}$ to form a gel at $37^{\circ} \mathrm{C}, 5 \%$ $\mathrm{CO}_{2}$. The thoracic aorta was excised from a 9-week-old male Sprague-Dawley rat (Charles River, Wilmington, MA, USA). The aorta was sectioned into $\sim 1$-mm long cross-sections, rinsed with EBM-2 medium (Lonza, Walkersville, MD, USA) eight times, placed on the Matrigel-coated wells, covered with an additional volume of $150 \mu \mathrm{l}$ Matrigel, and allowed $30-45 \mathrm{~min}$ to form a gel in an incubator at $37^{\circ} \mathrm{C}, 5 \% \mathrm{CO}_{2}$. The rings were cultured for $24 \mathrm{~h}$ in $1 \mathrm{ml}$ of EBM-2 supplemented with $10 \mu \mathrm{g} / \mathrm{ml} \mathrm{gentamicin}$ After incubation, the medium was removed and replaced with $1 \mathrm{ml}$ of EBM-2 supplemented with $2 \%$ FBS, gentamicin, and $10 \mu \mathrm{g} / \mathrm{ml}$ ES, ES-BAX, ES-BAK, or ES-BAX-ES, in triplicate. The medium was replaced every day. The aorta cultures were maintained at $37^{\circ} \mathrm{C}$ in a humidified, $5 \% \mathrm{CO}_{2}$ atmosphere. After 7 days of treatment, the cultures were washed three times in PBS, the medium was replaced with RPMI medium (Life Technologies Corporation) containing $5 \mathrm{mg} / \mathrm{ml}$ 3-(4,5-dimethylthiazol-2-y)2,5-diphenyltetrazolium bromide (MTT, Promega), and the culture was incubated for $2 \mathrm{~h}$. The supernatant was discarded, and digital images of the aortic rings were generated. The microvessel outgrowth area was quantified using the ImageJ (http:// imagej.nih.gov/ij) software. Images were analyzed by manually encircling the outgrowth area and computing the square pixels. This assay was repeated three times.

Animals and tumor induction. Male (24-27 g) BALB/c mice (6-7 weeks old, IPEN animal facility, IPEN, São Paulo, Brazil) were used. They were acclimated, caged in groups of five in a barrier care facility, and fed animal chow and water ad libitum. The manipulation of these animals before or during the experiments met the 'Principles of Laboratory Animal Care' (NIH Pub. No. 86-23, revised in 1985), the 'Principles of Ethics in Animal Experimentation' (Brazilian College of Animal Experimentation - COBEA), and Project No. 124/CEUA/IPEN/ SP Animal Research Ethics Committee authorization. We used a murine renal carcinoma cell line Renca (American Type Culture Collection, Manassas, VA, USA), a line of spontaneous origin derived from a BALB/C mouse kindly donated by Dr Isaiah Fidler, D.V.M., PhD. (University of Texas MD Anderson Cancer Center, USA). The left hind flank of the mice was subcutaneously (s.c.) injected with $2 \times 10^{5}$ Renca cells in $0.1 \mathrm{ml}$ of sterile PBS. Treatment started when each tumor reached $100 \mathrm{~mm}^{3}$. To this end, the mice received daily S.c. injections of $15 \mu \mathrm{g}$ of ES or ES-BAX/g of mice into the right flank for 10 days. Tumor dimensions were measured with an electronic caliper, and volumes were calculated as follows: tumor volume $=$ length $\times$ width $^{2} \times 0.52$. This assay was repeated twice.

Immunoprecipitation. HUV-EC-C cell lysates ( $10^{7}$ cells) were prepared by incubation with $1 \mathrm{ml}$ of lysis buffer $(50 \mathrm{mM}$ Tris- $\mathrm{HCl}$ at $\mathrm{pH} 8.0,0.15 \mathrm{M} \mathrm{NaCl}$, and $0.5 \%$ Triton X-100) containing $10 \%$ protease inhibitor cocktail (Sigma) for $30 \mathrm{~min}$ at $4^{\circ} \mathrm{C}$. The lysates were centrifuged, and the supernatants were incubated with $\mathrm{ES}$, ES-BAX, or ES-BAK $(100 \mu \mathrm{g} / \mathrm{ml})$ for $2 \mathrm{~h}$. Reactions were incubated with monoclonal anti-murine ES antibody (clone 1837.46, Merck Millipore, diluted 1:50), monoclonal anti-BCL-2 antibody (clone 4D7, Becton-Dickinson, diluted $1: 100$ ), or monoclonal anti-BCL- $\mathrm{X}_{\mathrm{L}}$ antibody (clone 2H12, Life Technologies, diluted $1: 100$ ) for $16 \mathrm{~h}$, at $4^{\circ} \mathrm{C}$. The co-immunoprecipitation was performed by incubation with $100 \mu \mathrm{l}$ of Protein G Agarose (Merck Millipore) for $4 \mathrm{~h}$, at $4^{\circ} \mathrm{C}$. The immune complexes were centrifuged and washed with lysis buffer three times. Immunoprecipitates and total cell extracts were subjected to SDS-PAGE; the proteins were transferred onto nitrocellulose membranes (GE Healthcare) and blocked. For the immunoblotting, ES, ES-BAX, and ES-BAK were detected with rabbit anti-ES polyclonal antibody (AB1880, Merck Millipore, diluted 1:500), antiBCL-2 (C-21: Sc-783, Santa Cruz Biotechnology, diluted 1:1000), anti-BCL-X (H-62: sc-50, Santa Cruz Biotechnnology, diluted 1:1000), anti-BAX (BectonDickinson, diluted 1:1000), or anti-BAK (Becton-Dickinson, diluted 1:1000), followed by incubation with HRP conjugated with secondary antibody (Merck Millipore, diluted 1:5000). Immunoprecipitated proteins were visualized by incubating the membranes with a chemiluminescence reagent (Immobilon, Merck Millipore) and exposing them to radiography films.

\section{Conflict of Interest}

The authors declare no conflict of interest.

Acknowledgements. This research was supported by grant from the State of São Paulo Research Foundation - FAPESP (Process 03/07949-4) and fellowship from National Council for Scientific and Technological Development - CNPq (Process 142401/2004-8). We thank Dr. Roger Chammas for critical comments and Dr. Daniel Perez for statistical analysis.

1. Boehm T, Folkman J, Browder T, O'Reilly MS. Antiangiogenic therapy of experimental cancer does not induce acquired drug resistance. Nature 1997; 390: 404-407.

2. Dixelius J, Larsson H, Sasaki T, Holmqvist K, Lu L, Engstrom A et al. Endostatin-induced tyrosine kinase signaling through the Shb adaptor protein regulates endothelial cell apoptosis. Blood 2000; 95: 3403-3411.

3. Sudhakar A, Sugimoto H, Yang C, Lively J, Zeisberg M, Kalluri R. Human tumstatin and human endostatin exhibit distinct antiangiogenic activities mediated by alpha $v$ beta 3 and alpha 5 beta 1 integrins. Proc Natl Acad Sci USA 2003; 100: 4766-4771. 
4. MacDonald NJ, Shivers WY, Narum DL, Plum SM, Wingard JN, Fuhrmann SR et al. Endostatin binds tropomyosin. A potential modulator of the antitumor activity of endostatin. J Biol Chem 2001; 276: 25190-25196.

5. Lee SJ, Jang JW, Kim YM, Lee HI, Jeon JY, Kwon YG et al. Endostatin binds to the catalytic domain of matrix metalloproteinase-2. FEBS Lett 2002; 519: 147-152.

6. Karumanchi SA, Jha V, Ramchandran R, Karihaloo A, Tsiokas L, Chan B et al. Cell surface glypicans are low-affinity endostatin receptors. Mol Cell 2001; 7: 811-822.

7. Javaherian K, Park SY, Pickl WF, LaMontagne KR, Sjin RT, Gillies S et al. Laminin modulates morphogenic properties of the collagen XVIII endostatin domain. J Biol Chem 2002; 277: 45211-45218.

8. Karamouzis MV, Moschos SJ. The use of endostatin in the treatment of solid tumors. Expert Opin Biol Ther 2009; 9: 641-648.

9. Celik I, Surucu O, Dietz C, Heymach JV, Force J, Hoschele I et al. Therapeutic efficacy of endostatin exhibits a biphasic dose-response curve. Cancer Res 2005; 65: 11044-11050.

10. Thomas JP, Arzoomanian RZ, Alberti D, Marnocha R, Lee F, Friedl A et al. Phase I pharmacokinetic and pharmacodynamic study of recombinant human endostatin in patients with advanced solid tumors. J Clin Oncol 2003; 21: 223-231.

11. Cory S, Adams JM. The Bcl2 family: regulators of the cellular life-or-death switch. Nat Rev Cancer 2002; 2: 647-656.

12. Amarante-Mendes GP, Green DR. The regulation of apoptotic cell death. Braz J Med Biol Res 1999; 32: 1053-1061.

13. Suzuki M, Youle RJ, Tjandra N. Structure of Bax: coregulation of dimer formation and intracellular localization. Cell 2000; 103: 645-654.

14. Moldoveanu T, Liu Q, Tocilj A, Watson M, Shore G, Gehring K. The X-ray structure of a BAK homodimer reveals an inhibitory zinc binding site. Mol Cell 2006; 24: 677-688.

15. Huang DC, Strasser A. BH3-Only proteins-essential initiators of apoptotic cell death. Cell 2000; 103: 839-842.

16. Willis SN, Adams JM. Life in the balance: how BH3-only proteins induce apoptosis. Curr Opin Cell Biol 2005; 17: 617-625.

17. Sattler M, Liang H, Nettesheim D, Meadows RP, Harlan JE, Eberstadt M et al. Structure of Bcl-xL-Bak peptide complex: recognition between regulators of apoptosis. Science 1997; 275: 983-986.

18. Gavathiotis E, Reyna DE, Davis ML, Bird GH, Walensky LD. BH3-triggered structural reorganization drives the activation of proapoptotic BAX. Mol Cell 2010; 40: 481-492.

19. Wei MC, Zong WX, Cheng EH, Lindsten T, Panoutsakopoulou V, Ross AJ et al. Proapoptotic BAX and BAK: a requisite gateway to mitochondrial dysfunction and death. Science 2001; 292: 727-730.

20. Kluck RM, Bossy-Wetzel E, Green DR, Newmeyer DD. The release of cytochrome c from mitochondria: a primary site for Bcl-2 regulation of apoptosis. Science 1997; 275: 1132-1136.

21. Green DR, Kroemer G. The pathophysiology of mitochondrial cell death. Science 2004; 305: 626-629.

22. Shangary S, Oliver CL, Tillman TS, Cascio M, Johnson DE. Sequence and helicity requirements for the proapoptotic activity of Bax BH3 peptides. Mol Cancer Ther 2004; $\mathbf{3}$ : 1343-1354.

23. Deng J, Carlson N, Takeyama K, Dal Cin P, Shipp M, Letai A. BH3 profiling identifies three distinct classes of apoptotic blocks to predict response to ABT-737 and conventional chemotherapeutic agents. Cancer Cell 2007; 12: 171-185.

24. Li R, Boehm AL, Miranda MB, Shangary S, Grandis JR, Johnson DE. Targeting antiapoptotic Bcl-2 family members with cell-permeable BH3 peptides induces apoptosis signaling and death in head and neck squamous cell carcinoma cells. Neoplasia 2007; 9 : 801-811.

25. Azar Y, Lorberboum-Galski H. GnRH-Bik/Bax/Bak chimeric proteins target and kill adenocarcinoma cells; the general use of pro-apoptotic proteins of the Bcl-2 family as novel killing components of targeting chimeric proteins. Apoptosis 2000; 5: 531-542.

26. van Delft MF, Wei AH, Mason KD, Vandenberg CJ, Chen L, Czabotar PE et al. The BH3 mimetic ABT-737 targets selective Bcl-2 proteins and efficiently induces apoptosis via $\mathrm{Bak} / \mathrm{Bax}$ if $\mathrm{Mcl}-1$ is neutralized. Cancer Cell 2006; 10: 389-399.
27. Song N, Ding Y, Zhuo W, He T, Fu Z, Chen Y et al. The nuclear translocation of endostatin is mediated by its receptor nucleolin in endothelial cells. Angiogenesis 2012; 15: 697-711.

28. Dhanabal M, Ramchandran R, Waterman MJ, Lu H, Knebelmann B, Segal M et al. Endostatin induces endothelial cell apoptosis. J Biol Chem 1999; 274: 11721-11726.

29. Kruger EA, Duray PH, Tsokos MG, Venzon DJ, Libutti SK, Dixon SC et al. Endostatin inhibits microvessel formation in the ex vivo rat aortic ring angiogenesis assay. Biochem Biophys Res Commun 2000; 268: 183-191.

30. Kisker O, Becker CM, Prox D, Fannon M, D'Amato R, Flynn E et al. Continuous administration of endostatin by intraperitoneally implanted osmotic pump improves the efficacy and potency of therapy in a mouse xenograft tumor model. Cancer Res 2001; 61: 7669-7674.

31. Shangary S, Johnson DE. Peptides derived from $\mathrm{BH} 3$ domains of $\mathrm{Bcl}-2$ family members: a comparative analysis of inhibition of $\mathrm{Bcl}-2, \mathrm{Bcl}-\mathrm{x}(\mathrm{L})$ and Bax oligomerization, induction of cytochrome $c$ release, and activation of cell death. Biochemistry 2002; 41: 9485-9495.

32. Miyashita T, Reed JC. Bcl-2 oncoprotein blocks chemotherapy-induced apoptosis in a human leukemia cell line. Blood 1993; 81: 151-157.

33. Takahashi M, Saito $\mathrm{H}$, Atsukawa $\mathrm{K}$, Ebinuma $\mathrm{H}$, Okuyama $\mathrm{T}$, Ishii $\mathrm{H}$. Bcl-2 prevents doxorubicin-induced apoptosis of human liver cancer cells. Hepatol Res 2003; 25: 192-201.

34. Tan C, Dlugosz PJ, Peng J, Zhang Z, Lapolla SM, Plafker SM et al. Auto-activation of the apoptosis protein Bax increases mitochondrial membrane permeability and is inhibited by Bcl-2. J Biol Chem 2006; 281: 14764-14775.

35. Willis SN, Fletcher Jl, Kaufmann T, van Delft MF, Chen L, Czabotar PE et al. Apoptosis initiated when BH3 ligands engage multiple Bcl-2 homologs, not Bax or Bak. Science 2007; 315: 856-859.

36. Gautier F, Guillemin Y, Cartron PF, Gallenne T, Cauquil N, Le Diguarher T et al. Bax activation by engagement with, then release from, the $\mathrm{BH} 3$ binding site of $\mathrm{Bcl}-\mathrm{xL}$. Mol Cell Biol 2011; 31: 832-844.

37. Letai A, Bassik MC, Walensky LD, Sorcinelli MD, Weiler S, Korsmeyer SJ. Distinct BH3 domains either sensitize or activate mitochondrial apoptosis, serving as prototype cancer therapeutics. Cancer Cell 2002; 2: 183-192.

38. Chen L, Willis SN, Wei A, Smith BJ, Fletcher JI, Hinds MG et al. Differential targeting of prosurvival $\mathrm{Bcl}-2$ proteins by their $\mathrm{BH}$-only ligands allows complementary apoptotic function. Mol Cell 2005; 17: 393-403.

39. Lessene G, Czabotar PE, Colman PM. BCL-2 family antagonists for cancer therapy. Nat Rev Drug Discov 2008; 7: 989-1000.

40. Petros AM, Nettesheim DG, Wang Y, Olejniczak ET, Meadows RP, Mack J et al. Rationale for $\mathrm{Bcl}-\mathrm{xL} / \mathrm{Bad}$ peptide complex formation from structure, mutagenesis, and biophysical studies. Protein Sci 2000; 9: 2528-2534.

41. Liu X, Dai S, Zhu Y, Marrack $\mathrm{P}$, Kappler JW. The structure of a $\mathrm{Bcl}-\mathrm{xL} / \mathrm{Bim}$ fragment complex: implications for Bim function. Immunity 2003; 19: 341-352.

42. Kunkel TA, Roberts JD, RA Zakour. Rapid and efficient site-specific mutagenesis without phenotypic selection. Methods Enzymol 1987; 154: 367-382.

43. Chura-Chambi RM, Genova LA, Affonso R, Morganti L. Refolding of endostatin from inclusion bodies using high hydrostatic pressure. Anal Biochem 2008; 379: 32-39.

(1) (2)(2) Cell Death and Disease is an open-access journal published by Nature Publishing Group. This work is licensed under a Creative Commons Attribution-NonCommercialShareAlike 3.0 Unported License. The images or other third party material in this article are included in the article's Creative Commons license, unless indicated otherwise in the credit line; if the material is not included under the Creative Commons license, users will need to obtain permission from the license holder to reproduce the material. To view a copy of this license, visit http://creativecommons.org/ licenses/by-nc-sa/3.0/

Supplementary Information accompanies this paper on Cell Death and Disease website (http://www.nature.com/cddis) 